Tropical Journal of Pharmaceutical Research September 2019; 18 (9): 1805-1809

ISSN: $1596-5996$ (print); 1596-9827 (electronic)

(c) Pharmacotherapy Group, Faculty of Pharmacy, University of Benin, Benin City, 300001 Nigeria.

\title{
Celastrol attenuates fMLP-induced superoxide anion generation, myeloperoxidase production, and elastase release by human neutrophils
}

\author{
Nipapan Malisorn*, Ammara Chaikan \\ Division of Pharmacology, Preclinical Sciences, Faculty of Medicine, Thammasat University, Pathumthani, Thailand
}

*For correspondence: Email: dr.nipapan@gmail.com; Tel: (+66)2-926-9716

Sent for review: 26 February 2019

Revised accepted: 19 August 2019

\begin{abstract}
Purpose: To investigate the anti-inflammatory effect of celastrol via attenuation of formyl-methionylleucyl-phenylalanine (fMLP)-induced superoxide generation, myeloperoxidase production, and elastase release by peripheral blood neutrophils.

Methods: Cytotoxicity of celastrol on human peripheral blood neutrophils was investigated using a $2 \mathrm{H}$ tetrazolium hydroxide (XTT) assay. Human neutrophils were stimulated with 100-nM fMLP; the effect of celastrol on superoxide generation was determined via ferricytochrome $C$ reduction, the effect on myeloperoxidase production by tetramethylbenzidine oxidation, and the effect on elastase activity by Boc-Ala-ONp hydrolysis.

Results: Treatment of human neutrophils with celastrol showed dose-dependent inhibition of fMLPinduced superoxide generation, myeloperoxidase production, and elastase release with half-maximal inhibitory concentration $\left(I C_{50}\right)$ values of $5.9 \pm 0.1,1.9 \pm 0.2$, and $1.5 \pm 0.1 \mu \mathrm{M}$, respectively.

Conclusion: These results indicate that celastrol possesses anti-inflammatory properties via attenuation of $\mathrm{fMLP}$-induced superoxide generation, myeloperoxidase production, and elastase release by peripheral blood neutrophils.
\end{abstract}

Keywords: Celastrol, Anti-inflammatory, Superoxide anion generation, Myeloperoxidase, Neutrophil elastase

\begin{abstract}
This is an Open Access article that uses a fund-ing model which does not charge readers or their institutions for access and distributed under the terms of the Creative Commons Attribution License (http://creativecommons.org/licenses/by/4.0) and the Budapest Open Access Initiative (http://www.budapestopenaccessinitiative.org/read), which permit unrestricted use, distribution, and reproduction in any medium, provided the original work is properly credited.

Tropical Journal of Pharmaceutical Research is indexed by Science Citation Index (SciSearch), Scopus, International Pharmaceutical Abstract, Chemical Abstracts, Embase, Index Copernicus, EBSCO, African Index Medicus, JournalSeek, Journal Citation Reports/Science Edition, Directory of Open Access Journals (DOAJ), African Journal Online, Bioline International, Open-J-Gate and Pharmacy Abstracts
\end{abstract}

\section{INTRODUCTION}

Inflammation is a vital part of the immune response to insults ranging from trauma to infection. However, prolonged or unregulated inflammation contributes to the pathology of many diseases (e.g., arthritis [1], cancer [2], emphysema [3], and vasculitis [4]).
Neutrophils are crucial elements of cell-mediated immune responses, playing an important role in inflammation [5]. They are recruited to the site of damage within seconds and then destroy invading microorganisms by phagocytosis and digestion, which generate the toxic oxygen metabolite superoxide $\left(\mathrm{O}_{2}{ }^{\circ-}\right)$ from NADPH oxidase [6]. Thus, uncontrolled neutrophil activation produces excessive toxic oxygen metabolites that damage the host's own tissues 
[7]. Furthermore, neutrophil activation also liberates myeloperoxidase and elastase; myeloperoxidase catalyzes a halogenation reaction, generating a toxic end-product, hypochlorous acid, and elastase denatures elastin and collagen, which inhibits healing and the resolution of inflammation $[8,9]$. Obviously data showed that non-steroidal anti-inflammatory drugs (NSAIDs), such as indomethacin, could inhibit superoxide generation, myeloperoxidase production, and elastase release. Several studies have established that celastrol has therapeutic effect on inflammatory diseases including asthma, rheumatoid arthritis, and amyotrophic lateral sclerosis [10-12]. However, limited data exist regarding the effects of this compound on human neutrophil function.

The aim of this study was to determine whether celastrol can inhibit formyl-methionyl-leucylphenylalanine (fMLP)-induced inflammatory processes by peripheral blood neutrophils.

\section{EXPERIMENTAL}

\section{Materials}

All chemicals were obtained from Sigma Aldrich (USA) unless stated otherwise. Celastrol was purchased from TOCRIS Bioscience (USA).

\section{Isolation of peripheral blood human neutrophils}

This study was approved by ethical review board of Faculty of Medicine, Thammasat University, Thailand [13] with a certificate no. 074/2560. Human neutrophils were isolated by a discontinuous Percoll gradient method [14]. Neutrophils were re-suspended in RPMI 1640 for measurement of neutrophil cytotoxic assay or in phosphate buffered saline for measurement of superoxide generation, myeloperoxidase production, and elastase release.

\section{Cytotoxicity assay}

Neutrophils were treated with celastrol or indomethacin (final concentration of $0.1-1,000$ $\mu \mathrm{M}$ ) or RPMI 1640 (control) for $4 \mathrm{~h}$ at $37^{\circ} \mathrm{C}$. Then, $2 \mathrm{H}$-tetrazolium hydroxide was added, and the mixture was incubated for $3 \mathrm{~h}$ at $37^{\circ} \mathrm{C}$. Cell viability was evaluated at $450 \mathrm{~nm}$ using a BioTex microplate reader [15]. Each reaction mixture was performed in triplicate. Percentage of cell cytotoxicity was convert from \% cell viability, 100 - ((OD sample - OD medium) / (OD control - OD medium) x $100 \%$ ).

\section{Determination of superoxide generation}

Neutrophils were treated with celastrol or indomethacin (final concentration of $0.1-100 \mu \mathrm{M}$ ) or phosphate buffered saline (control) at $37^{\circ} \mathrm{C}$ for 10 min. fMLP (100 nM) was then added, incubated at $37{ }^{\circ} \mathrm{C}$ for $10 \mathrm{~min}$. Superoxide generation was determined via ferricytochrome $\mathrm{C}$ reduction at $550 \mathrm{~nm}$ using a BioTex microplate reader [14]. Results were reported as percent inhibition of superoxide.

\section{Determination of myeloperoxidase production}

Neutrophils were treated with celastrol or indomethacin (final concentration of $0.1-100 \mu \mathrm{M}$ ) or phosphate buffered saline (control) at $37^{\circ} \mathrm{C}$ for 10 min. fMLP (100 nM) was then mixed and incubated at $37{ }^{\circ} \mathrm{C}$ for $10 \mathrm{~min}$. Supernatants were treated with tetramethylbenzidine (TMB) mixture at $37{ }^{\circ} \mathrm{C}$ for $7 \mathrm{~min}$. Myeloperoxidase production was measured via oxidation of tetramethylbenzidine and assessed at $450 \mathrm{~nm}$ using a BioTex microplate reader [16]. Results were reported as percent inhibition of myeloperoxidase production.

\section{Evaluation of elastase release}

Neutrophils were treated with celastrol or indomethacin (final concentration of $0.1-100 \mu \mathrm{M}$ ) or phosphate buffered saline (control) at $37^{\circ} \mathrm{C}$ for $10 \mathrm{~min}$. fMLP $(100 \mathrm{nM})$ was then added, incubated at $37^{\circ} \mathrm{C}$ for $10 \mathrm{~min}$. The supernatants were treated with Boc-Ala-ONp at $37^{\circ} \mathrm{C}$ for 20 min. Elastase activity was assayed via the hydrolysis of Boc-Ala-ONp at $405 \mathrm{~nm}$ using BioTex microplate reader [17]. Results were reported as percent inhibition of elastase release.

\section{Statistical analysis}

Results are reported as mean \pm SEM. Statistical significance $(p<0.05)$ was detected by one-way ANOVA using GraphPad Prism 8.1.2 (GraphPad Prism, CA), followed by Student-Newman-Keuls analysis.

\section{RESULTS}

\section{Cytotoxicity}

The incubation of human neutrophils with 0.1$100 \mu \mathrm{M}$ of celastrol or indomethacin caused no cytotoxic effects. However, at 1,000 $\mu \mathrm{M}$, both celastrol and indomethacin caused cytotoxicity $(26.8 \pm 2.0 \%$ and $3.8 \pm 0.4 \%$, respectively) (Figure 1). 


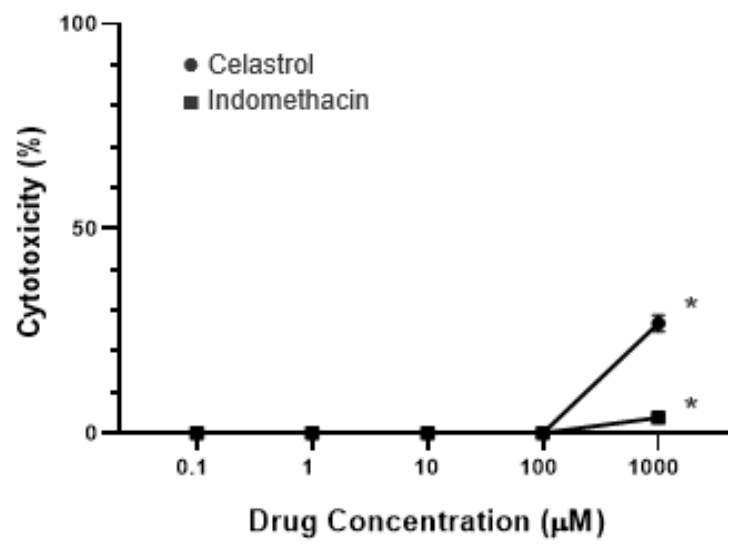

Figure 1: Cytotoxicity of celastrol or indomethacin $(0.1-1,000 \mu \mathrm{M})$ on human peripheral blood neutrophils. Results are reported as mean \pm SEM $(n=$ $7) ;{ }^{*} p<0.05$ when compared with control cells

\section{Superoxide generation}

Celastrol suppressed fMLP-induced superoxide generation in a dose-dependent manner and did so more strongly $\left(\mathrm{IC}_{50}=5.9 \pm 1.0 \mu \mathrm{M}\right)$ than indomethacin $\left(\mathrm{IC}_{50}=16.4 \pm 3.5 \mu \mathrm{M}\right)$ (Figure 2); this effect was significant at concentrations of 1$10 \mu \mathrm{M}(p<0.05)$. However, at $100 \mu \mathrm{M}$, indomethacin exhibited significantly stronger inhibition of fMLP - induced superoxide generation than celastrol $(p<0.05$; Figure 2$)$.

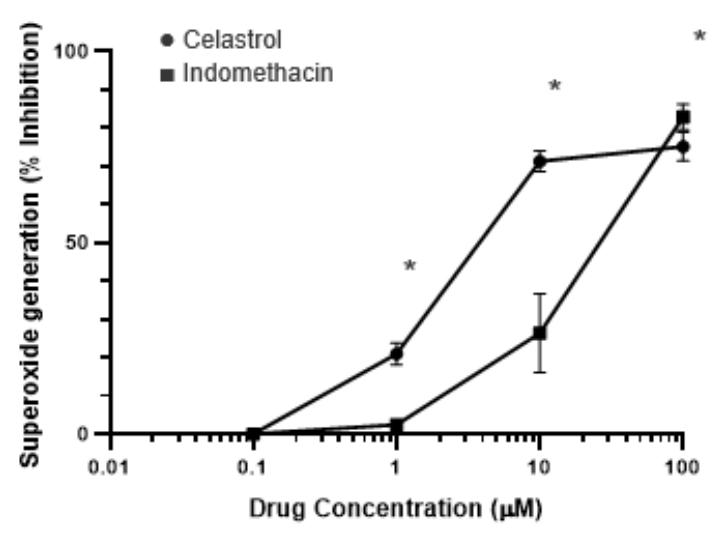

Figure 2: Inhibitory effect of celastrol and indomethacin on fMLP-induced superoxide generation in human peripheral blood neutrophils. Results are reported as mean \pm SEM $(\mathrm{n}=7) ;{ }^{*} p<0.05$ for comparison of indomethacin vs. celastrol

\section{Myeloperoxidase production}

Celastrol inhibited fMLP-induced myeloperoxidase production in a dose-dependent manner that was stronger than indomethacin $\left(\mathrm{IC}_{50}: 1.9 \pm\right.$ $0.2 \mu \mathrm{M}, 50.7 \pm 1.3 \mu \mathrm{M}$, respectively) (Figure 3), and these differences were statistically significant at concentrations of $1-100 \mu \mathrm{M}(p<0.05)$.

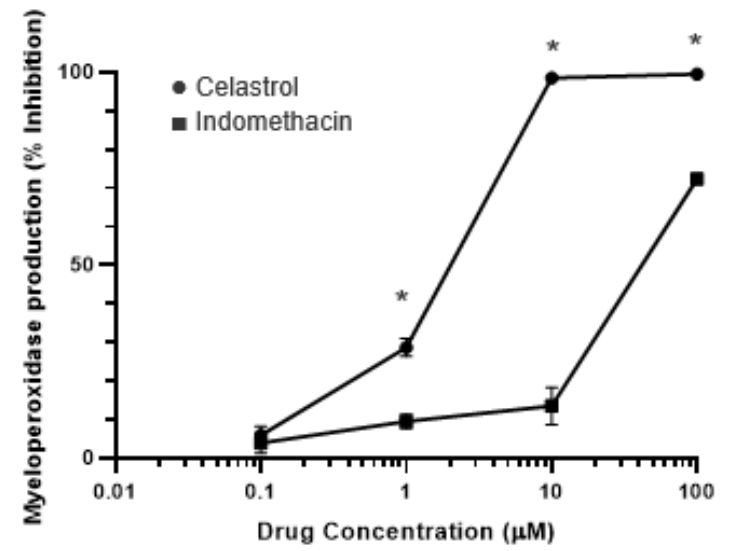

Figure 3: Inhibitory effect of celastrol on fMLP-induced myeloperoxidase production in human peripheral blood neutrophils. Results are reported as mean \pm SEM $(n=7)$; ${ }^{*} p<0.05$ for comparison of indomethacin vs. celastrol

\section{Elastase release}

Celastrol suppressed fMLP-induced elastase release in a dose-dependent manner. Celastrol had a stronger inhibition $\left(\mathrm{IC}_{50}=1.5 \pm 0.1 \mu \mathrm{M}\right)$ than indomethacin $\left(\mathrm{IC}_{50}=15.7 \pm 2.7 \mu \mathrm{M}\right.$ ) (Figure 4 ), and the inhibitory effect of celastrol was significantly better than indomethacin at concentrations of $0.1-100 \mu \mathrm{M}(p<0.05)$.

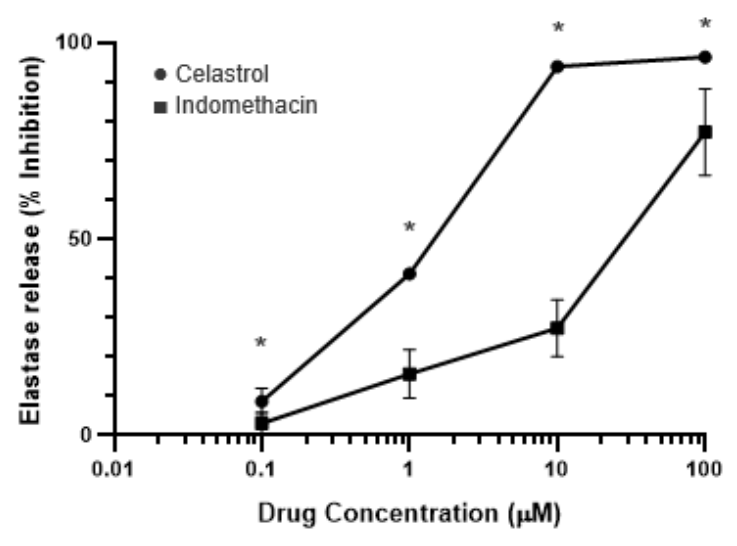

Figure 4: Inhibitory effect of celastrol on $\mathrm{AMLP}$-induced elastase release in human peripheral blood neutrophils. Results are reported as mean \pm SEM ( $n=$ $7) ;{ }^{*} p<0.05$ for comparison of indomethacin vs. celastrol

\section{DISCUSSION}

In inflammation, neutrophils are recruited to the damaged site by fMLP; upon arrival, neutrophils degranulate, generating superoxide, myeloperoxidase, and elastase to destroy pathogens. fMLP is a potent chemotactic substance [19] that attracts and activates neutrophils, which, in turn, liberate superoxide 
through NADPH oxidase activity [20]. Unregulated, this degranulation contributes to tissue destruction [18]. Although previous work demonstrates that celastrol completely inhibits NADPH oxidase enzymes [21], our study showed that celastrol inhibits fMLP-induced superoxide generation by peripheral blood neutrophils is dose-dependent, with maximum inhibitory effects achieved at a concentration of $100 \mu \mathrm{M}$.

Myeloperoxidase, regarded as a crucial biomarker of inflammatory diseases (e.g., as rheumatoid arthritis, sinusitis and colitis [24-26]), produces many reactive oxidants, such as hypochlorous acid, by consuming hydrogen peroxide and chloride anion [23]. Although nonsteroidal anti-inflammatory drugs (NSAIDs), including indomethacin, diclofenac, naproxen, and piroxicam, inhibit myeloperoxidase [27], our study showed that celastrol also inhibits fMLP induced myeloperoxidase production in a dosedependent manner.

Elastase [28], another causative factor in inflammatory disease, is also suppressed by NSAIDs. Here, we demonstrated that celastrol too suppresses neutrophil elastase release in a concentration-dependent manner.

\section{CONCLUSION}

In human neutrophils, celastrol significantly inhibited fMLP-induced superoxide generation, myeloperoxidase production, and elastase release in a dose-dependent manner. These effects might be attributed, at least in part, to its anti-inflammatory activity. Therefore, celastrol may be a promising candidate substance for further development as an anti-inflammatory therapy.

\section{DECLARATIONS}

\section{Acknowledgement}

This study was supported by Faculty of Medicine, Thammasat University Research Fund (no. 225/2560).

\section{Conflict of interest}

No conflict of interest is associated with this work.

\section{Contribution of authors}

We declare that this work was done by the authors named in this article and all liabilities pertaining to claims relating to the content of this article will be borne by the authors.

\section{Open Access}

This is an Open Access article that uses a funding model which does not charge readers or their institutions for access and distributed under the terms of the Creative Commons Attribution License (http://creativecommons.org/licenses/by/ 4.0) and the Budapest Open Access Initiative (http://www.budapestopenaccessinitiative.org/rea d), which permit unrestricted use, distribution, and reproduction in any medium, provided the original work is properly credited.

\section{REFERENCES}

1. Issekutz AC, Issekutz TB. Quantitation and kinetics of polymorphonuclear leukocyte and lymphocyte accumulation in joints during adjuvant arthritis in the rat. Lab Invest 1991; 64: 656-663.

2. Weitzman SA, Gordon LI. Inflammation and cancer: role of phargocyte-generated oxidants in carcinogenesis. Blood 1990; 76: 655-663.

3. Hogg JC. Neutrophil kinetics and lung injury. Physiol Rev 1989; 67: 1249-1495.

4. Warren JS, Yabroff KR, Mandel DM, Johnson KJ, Ward $P A$. Role of $\mathrm{O2}$ - in neutrophil recruitment into sites of dermal and pulmonary vasculitis. Free Radic Biol Med 1990; 8: 163-172.

5. Smith JA. Neutrophils, host defense, and inflammation: a double-edged sword. J Leukoc Biol 1994; 56: 672-686.

6. Brandes RP, Weissmann $N$, Schröder K. Nox family NADPH oxidases: Molecular mechanisms of activation. Free Radic Biol Med 2014; 76: 208-226.

7. Babior BM. Phagocytes and oxidative stress. Am J Med 2000; 109: 33-44.

8. Furtmuller PG, Burner $U$, Obinger $C$. Reaction of myeloperoxidase compound I with chloride, bromide, iodide and thiocyanate. Biochem 1998; 37: 1792317930.

9. Fujie $K$, Shinguh $Y$, Inamura $N$, Yasumitsu $R$, Okamoto $M$, Okuhara M. Release of neutrophil elastase and its role in tissue injury in acute inflammation: effect of the elastase inhibitor, FR 134043. Eur J Pharmacol 1999; 374: 117-125.

10. Kim DY, Park JW, Jeoung D, Ro JY. Celastrol suppresses allergen-induced airway inflammation in mouse allergic asthma model. Eur J Pharmacol 2009; 612: 98-105.

11. Kiaei M, Kipiani K, Petri S, Chen J, Calingasan NY, Beal MF. Celastrol blocks neuronal cell death and extends life in transgenic mouse model of amyotrophic lateral sclerosis. Neurodegenerative Dis 2005; 2: 246-254.

12. Li H, Zhang YY, Tan HW, Jia YF, Li D. Therapeutic effect of tripterine on adjuvant arthritis in rats. $J$ Ethnopharmacol 2008; 118: 479-484.

Trop J Pharm Res, September 2019; 18(9): 1808 
13. Sumalee $P$, Srisopa R, Pakakrong $T$, Busarawan $S$, Arunporn I. Immunomodulatory activity of Dioscorea membranacea Pierre rhizomes and of its main active constituent Dioscorealide B. BMC Complement Altern Med 2014; 14: 403.

14. Talpain E, Armstrong RA, Coleman RA, Vardey CJ. Characterization of $P G E$ receptor subtype mediating inhibition of superoxide production in human neutrophils. Br J Pharmacol 1995; 114: 1459-1465.

15. Mosmann T. Rapid colorimetric assay for cellular growth and survival: Application to proliferation and cytotoxicity assays. J Immunol Methods 1983; 65: 55-63.

16. Bozeman PM, Learn DB, Thomas EL. Assay of the human leukocyte enzymes myeloperoxidase and eosinophil peroxidase. J Immunol Methods 1990; 126 : 125-133.

17. Clark JM, Aiken BM, Vaughan DW, Kagan HM. Ultrastructural localization of elastase-like enzymes in human neutrophils. J Histochem Cytochem 1980; 28 : 90-92.

18. Mortaz E, Alipoor SD, Adcock IM, Mumby S, Koenderman L. Update on Neutrophil Function in Severe Inflammation. Front Immunol 2018; 9: 2171.

19. Liang SL, Woodlock TJ, Whitin JC, Lichtman MA, Segel $G B$. Signal transduction in $\mathrm{N}$-formyl-methionyl-leucylphenylalanine and concanavalin. A stimulated human neutrophils: superoxide production without a rise in intracellular free calcium. J Cell Physiol 1990; 145: 295 302.
20. Karlsson A, Nixon JB, McPhail LC. Phorbol myristate acetate induces neutrophil NADPH-oxidase activity by two separate signal transduction pathways: dependent or independent of phosphatidyl-inositol 3-kinase. J Leukoc Biol 2000; 67: 396-404.

21. Vincent J, Julien M, Eric F, Kevin GL, Sally M, Yvonne W, Remo $P$, Olivier $P$, Laetitia FC, Becky D, Leonardo $S$, William MN, Franck F, Krause KH, Karen B. NADPH oxidase (NOX) isoforms are inhibited by celastrol with a dual mode of action. Br J Pharmacol 2011; 164: 507520.

22. Zipfel M, Carmine TC, Gerber C, Niethammer D, Bruchelt $G$. Evidence for the activation of myeloperoxidase by $f$ Meth-Leu-Phe prior to its release from neutrophil granulocytes. Biochem Biphy Res Commun 1997; 232: 209-212.

23. Davies MJ. Myeloperoxidase-derived oxidation: Mechanisms of biological damage and its prevention. $J$ Clin Biochem Nutr 2011; 48: 8-19.

24. Fernandes RM, da Silva NP, Sato El. Increased myeloperoxidase plasma levels in rheumatoid arthritis. Rheumatol Int 2012; 32(6): 1605-1609.

25. Haxel BR, Woywode C, Mewes T, Mann WJ. Myeloperoxidase in nasal secretion as a cell-activation marker in acute sinusitis. Am J Rhinol 2004; 18(2): 9398.

26. David RH, Kush S, Prateek A, Nitin A. Fecal Myeloperoxidase as a Biomarker for Inflammatory Bowel Disease. Cureus 2017; 9(1): e1004. 